\title{
Prolactin family miniarray: a tool for evaluating uteroplacental-trophoblast endocrine cell phenotypes
}

\author{
G. Dai*, L. Lu, S. Tang, M. J. Peal and M. J. Soares ${ }^{\dagger}$ \\ Institute of Maternal-Fetal Biology, Departments of Molecular and Integrative Physiology and \\ Obstetrics and Gynecology, The University of Kansas Medical Center, Kansas City,
}

KS 66160, USA

The prolactin family represents a group of hormones and cytokines that participate in the control of maternal and fetal adaptations to pregnancy. The aim of this study was to develop a simple assay for monitoring patterns of prolactin family gene expression in rats and mice. Prolactin family cDNAs were spotted on to nylon membranes. Total RNA was extracted from tissues or cells. cDNAs were generated, radiolabelled using reverse transcriptase, and used as probes to hybridize with the prolactin family miniarrays. Pituitary, uterine decidual tissue and placenta each expressed a unique profile of prolactin family members.
Placental tissues exhibited regional- and temporal-specific patterns of expression. Prolactin family gene expression differed markedly in mid-pregnant versus late gestation placental tissues and between the junctional and labyrinthine zones of the chorioallantoic placenta. Marked changes in prolactin family gene expression were also observed in cultured trophoblast cells undergoing differentiation. In conclusion, the prolactin family miniarray assay is an effective method for evaluating the endocrine phenotype of the uterus, placenta and trophoblast cells.

\section{Introduction}

The uterus and the placenta influence the maternal-fetal interface by their production of hormones and cytokines. Among the various regulatory signals secreted by the uterus and placenta is a prominent family of proteins related to pituitary prolactin and known as the uteroplacental prolactin family (Soares and Linzer, 2001). At least 19 different ligands bearing some similarity to prolactin have been identified in mice and rats, including placental lactogens (PLs), prolactin-like proteins (PLPs), prolactin-related protein (PRP), proliferin and proliferin-related protein (PLF-RP). This gene family encodes proteins with a diverse array of biological actions implicated in the establishment and maintenance of pregnancy (Soares and Linzer, 2001). These actions include the regulation of ovarian and mammary gland function and inflammatory, immune, endothelial and hematopoietic cell development and function. There are three major types of cell involved in the biosynthesis of members of the uteroplacental prolactin family in rats and mice: (i) lactotrophs of the anterior pituitary; (ii) decidual cells of the uterus; and (iii) trophoblast cells of the placenta (Soares et al., 1991, 1996, 1998). Members of the prolactin family are expressed in cell- and temporal-specific patterns in the uteroplacental compartment and anterior pituitary (Soares and Linzer,

*Present address: Department of Internal Medicine, The University of Texas Medical Branch at Galveston, 301 University Boulevard, TX 77555-1064, USA

+Correspondence

Email: msoares@kumc.edu
2001). In this report, a simple array-based hybridization assay for monitoring gene expression of the mouse and rat prolactin gene family is described. The assay permits the phenotyping of uteroplacental tissues and trophoblast cells.

\section{Materials and Methods}

\section{Animals and tissue dissections}

Holtzman rats were obtained from Harlan SpragueDawley Inc. (Indianapolis, IN). CD-1 mice were purchased from Charles River Laboratories Inc. (Wilmington, MA). Animals were housed in an environmentally controlled facility, with lights on from 06:00 to 20:00 h and were allowed free access to food and water. Timed pregnancies were generated by cohabitation of female and male animals. The presence of a copulatory plug or spermatazoa in vaginal smears was designated day 0 of pregnancy in rats. Rat uteroplacental tissues were dissected as described by Faria et al. (1990). The presence of a copulatory plug was designated day 1 of pregnancy in mice. Mouse uteroplacental tissues were dissected as described by Orwig et al. (1997) and Dai et al. (1998). The University of Kansas Animal Care and Use Committee approved protocols for the care and use of animals.

\section{Rcho-1 trophoblast cell line}

Elucidation of regulatory networks controlling trophoblast cell differentiation has been facilitated by the availability of the rat Rcho-1 trophoblast cell line (Faria and Soares, 1991; Peters et al., 2000). Rcho-1 trophoblast cells 
can be manipulated to proliferate or to differentiate along the trophoblast giant cell lineage (Faria and Soares, 1991; Hamlin et al., 1994; Peters et al., 2000). The Rcho-1 trophoblast cell line was routinely maintained in subconfluent conditions with RPMI-1640 culture medium supplemented with $20 \%$ fetal bovine serum (FBS; JRH Biosciences, Lenexa, KS) as reported by Faria and Soares (1991), Hamlin et al. (1994) and Peters et al. (2000). Differentiation was induced by growing cells to near confluence in FBS-supplemented culture medium and then replacing the medium with NCTC135 culture medium supplemented with $10 \%$ horse serum (HS; JRH Biosciences). High cell density and the absence of sufficient growth stimulatory factors (removal of FBS) facilitate trophoblast giant cell formation (Hamlin et al., 1994; Hamlin and Soares, 1995; Peters et al., 2000).

\section{Trophoblast stem cells}

Trophoblast stem (TS) cells represent a population of cells derived from the mouse blastocyst with the capability to differentiate into all trophoblast cell lineages (Tanaka et al., 1998). TS cells were obtained from J. Rossant, Mount Sinai Hospital (Toronto, Canada). Rossant and co-workers have previously demonstrated that heparin and fibroblast growth factor 4 (FGF-4) stimulate proliferation of TS cells and inhibit differentiation (Tanaka et al., 1998). TS cells were maintained in heparin-FGF-4 supplemented culture medium comprising 30\% TS medium (RPMI-1640 supplemented with $20 \%$ FBS, 1 mmol sodium pyruvate $\mathrm{I}^{-1}$, $50 \mu \mathrm{mol} 2$-mercaptoethanol $\mathrm{I}^{-1}$ ) and $70 \%$ mouse embryonic fibroblast conditioned medium as described by Tanaka et al. (1998). Heparin and FGF-4 were obtained from Sigma Chemical Co. (St Louis, MO) and added to final concentrations of $1 \mu \mathrm{g} \mathrm{ml}^{-1}$ and $25 \mathrm{ng} \mathrm{ml}^{-1}$, respectively. These culture conditions promoted the optimal proliferation of TS cells (Tanaka et al., 1998). Culturing the cells in culture medium devoid of FGF-4, heparin and embryonic fibroblast conditioned culture medium induces trophoblast differentiation (Tanaka et al., 1998).

\section{Preparation of prolactin family DNA miniarrays}

Miniarray assays for the mouse and rat prolactin families have been established. Each of the cDNAs corresponding to the mouse and rat prolactin gene families were acquired from Research Genetics (Huntsville, AL); American Type Culture Collection (Rockville, MD); D. I. H. Linzer (Northwestern University, Evanston, IL) or K. Shiota (University of Tokyo), or were cloned by our laboratory (Tables 1 and 2). Oligonucleotide primers were designed that specifically amplify cDNAs corresponding to the nucleotide sequences encoding the mature proteins. Nucleotide regions corresponding to $5^{\prime}$ and 3' untranslated regions and signal peptides were excluded. Additional DNAs, including salmon sperm DNA and glyceraldehyde-3-phosphate dehydrogenase (G3PDH) were used as negative and positive controls, respectively. cDNAs were amplified using the polymerase chain reaction (PCR) with corresponding oligonucleotide primers
(GenoMechanix, Alachua, FL; Tables 1 and 2) and prolactin family cDNA templates. Plasmid DNA (5 ng) was used in $100 \mu \mathrm{l}$ PCR reaction containing $1 \times$ PCR buffer (Life Technologies, Rockville, MD), $1.5 \mathrm{mmol} \mathrm{MgCl}_{2} \mathrm{I}^{-1}, 1 \mathrm{mmol}$ dNTPs $\mathrm{I}^{-1}, 0.2 \mu \mathrm{mol} \mathrm{I}^{-1}$ each primer and 5 units of Taq DNA polymerase (Life Technologies). Initial denaturation was at $95^{\circ} \mathrm{C}$ for $5 \mathrm{~min}$, followed by 35 cycles of denaturation at $94^{\circ} \mathrm{C}$ for $30 \mathrm{~s}$, annealing at 50 to $65^{\circ} \mathrm{C}$ for $1 \mathrm{~min}$ and extension at $72^{\circ} \mathrm{C}$ for $1 \mathrm{~min}$, followed by the final extension at $72^{\circ} \mathrm{C}$ for $3 \mathrm{~min}$. Aliquots of these PCR products were separated by electrophoresis on $1.5 \%$ agarose gels to verify their size and purity. PCR products were purified with the Qiagen PCR purification kit (Qiagen, Valencia, CA), and then quantified with a spectrophotometer at an absorbance of $260 \mathrm{~nm}$. PCR products were denatured by boiling for 5 min and immediately chilling on ice. Purified PCR products (20 ng per well) were spotted on nylon filters (Schleicher \& Schuell, Keene, NH) with a dot blot apparatus (Bio-Rad, Hercules, CA).

\section{RNA isolation and labelling}

Total RNA was extracted from tissues or cultured cells using the Trizol reagent (Life Technologies; Chomczynski and Sacchi, 1987). RNA samples were quantified by spectrophotometry and then separated by electrophoresis in 1\% agarose to determine their integrity. Total RNA was labelled according to Mammalian GeneFilters Microarrays Protocol (Research Genetics). Total RNA (10 $\mathrm{g}$ per sample) was primed with $2 \mu \mathrm{g}$ oligo dT (Research Genetics) in $10 \mu \mathrm{l}$ total volume by heating at $70^{\circ} \mathrm{C}$ for $10 \mathrm{~min}$ and then chilling briefly on ice. Elongation reactions were performed in $1 \times$ First Strand Buffer (Life Technologies), $3.3 \mathrm{mmol}$ DTT $\mathrm{I}^{-1}$ (Life Technologies), $1 \mathrm{mmol}^{-1}$ each of dATP, dGTP, dTTP (Amersham Pharmacia Biotech, Piscataway, NJ), 300 units of Superscript II Reverse Transcriptase (Life Technologies) and $3.3 \mathrm{mCi}\left[\alpha_{-}{ }^{32} \mathrm{P}\right]$ per $\mathrm{mmol}$ dCTP per litre (PerkinElmer Life Science, Boston, MA) in a total volume of $30 \mathrm{I}$ at $37^{\circ} \mathrm{C}$ for $90 \mathrm{~min}$. Probes were purified with micro Bio-Spin 30 chromatography columns (Bio-Rad) and then boiled for 5 min before use.

\section{Hybridization and analysis}

Prehybridization was performed at $42^{\circ} \mathrm{C}$ for $4 \mathrm{~h}$ in a prehybridization solution containing 50\% formamide, $6 \times$ sodium chloride sodium phosphate EDTA buffer (SSPE), $5 \times$ Denhardt's reagent, $0.5 \%$ SDS and $100 \mu \mathrm{g}$ salmon sperm DNA ml-1. Hybridizations were carried out at $42^{\circ} \mathrm{C}$ overnight by adding probe to the prehybridization solution. Membranes were washed twice for 15 min each in $2 \times$ SSPE and $0.5 \%$ SDS at $42^{\circ} \mathrm{C}$ followed by stringent washing in prewarmed $0.1 \times \mathrm{SSPE}$ and $0.1 \% \mathrm{SDS}$ at $68^{\circ} \mathrm{C}$ for $30 \mathrm{~min}$. Membranes were dried and exposed to X-ray film (Eastman Kodak Co., Rochester, NY) at $-80^{\circ} \mathrm{C}$ or placed in Phosphorlmager cassettes (Amersham Pharmacia Biotech) and quantified using the ImageQuant software (Version 4.2A, Molecular Dynamics, Sunnyvale, CA). 
Table 1. Primer sets used for members of the mouse prolactin gene family

\begin{tabular}{|c|c|c|c|c|}
\hline Gene & $\begin{array}{c}\text { GenBank } \\
\text { accession number }\end{array}$ & Forward primer & Reverse primer & $\begin{array}{l}\text { Product size } \\
\text { (bp) }\end{array}$ \\
\hline Prolactin & X02892 & 5' ССТСТGССААТСТGTTCСGСТ 3' & 5' TTAGCAGTTGTTTTGATGGGC 3' & 596 \\
\hline PL-I & M35662 & 5' GCCCACTGAAGACCTGTATAC 3' & 5' TGAAAGACAACTCGGCACCTC 3' & 554 \\
\hline PL-II & M14647 & 5' TATCGATTACCCACTGAAAGC 3' & 5' TTATGAACATCACGACACTTC 3' & 553 \\
\hline Proliferin & K02245 & 5' ATGATTTTGGATGCCTGGGAA 3' & 5' AACATGTAACACTTCAGGACG 3' & 313 \\
\hline Proliferin-RP & X02594 & 5' GTGTCCTCTGCACCСАTAAAT 3' & 5' AAATTCAGAGTAGCAGACATC 3' & 650 \\
\hline PLP-A & AF015562 & 5' GCTAAAAGGTTGAATGTCCAC 3' & 5' GCAGTTGCTTTGGATCAGTCG 3' & 581 \\
\hline PLP-B & AF015563 & 5' GTGCCCATGTATGCCAGTTTG 3' & 5' GCACTTCAAAAGCCTGATACT 3' & 578 \\
\hline PLP-C $\alpha$ & AF090140 & 5' AATCTTCCATGTGTTGCAGAA 3' & 5' GCAATCTTTCCCAGTTATGAG 3' & 629 \\
\hline PLP-C $\beta$ & AF158744 & 5' CATGCAGACAGCTGGAACCCT 3' & 5' ACATTTCCAAAACAGTCAGGG 3' & 604 \\
\hline PLP-C $\gamma$ & AF466150 & 5' GCATGTATGGCAGAAAAGAGC 3' & 5' ACAGCTCTGCAATGAACTTTT 3' & 687 \\
\hline $\mathrm{d} / \mathrm{tPRP}$ & AF015729 & 5' TGAATGTCAAACAGGAGAGAA 3' & 5' CAATCTTGCCCAGTTATGCGG 3' & 626 \\
\hline PLP-E & AF020525 & 5' CTACСТTTAAGCAGCAATGAT 3' & 5' AGTTTTGGAAGATAAGCAGCT 3' & 695 \\
\hline PLP-F & AF020524 & 5' AGCAATGAGACTGATGGTTAT 3' & 5' TGAAGCATCTCTAATATTTTTGGA 3' & 656 \\
\hline PLP-J & AB019118 & 5' TATGACCGGAAATCCAATGAA 3' & 5' GGTTTTGATTTTGCCATGCTT 3' & 536 \\
\hline PLP-K & AY077703 & 5' TGGTCTGGACTGGCATCTTTG 3' & 5' AGTACTTCCAAGCAATTTTTATTTT 3' & 259 \\
\hline PLP-L & AF226611 & 5' ATCATGGAAGATGGAGGTTGC 3' & 5' GCACAATTTGGTCTCTCAGGA 3' & 579 \\
\hline PLP-M & AF234636 & 5' CCCATATGCTCAGTAAGGAAT 3' & 5' TTTGCATTTCACCATCTTGAG 3' & 572 \\
\hline
\end{tabular}

$\mathrm{PL}$, placental lactogen; proliferin-RP, proliferin-related protein; PLP, prolactin-like protein; d/tPRP, decidual-trophoblast prolactin-related protein.

Table 2. Primer sets used for members of the rat prolactin gene family

\begin{tabular}{|c|c|c|c|c|}
\hline Gene & $\begin{array}{c}\text { GenBank } \\
\text { accession number }\end{array}$ & Forward primer & Reverse primer & $\begin{array}{l}\text { oduct size } \\
\text { (bp) }\end{array}$ \\
\hline Prolactin & V01249 & 5' CTGTTCTGGTGGCGACTGC 3' & 5' GTTTTTATGGACAATTTGGCACCTC 3' & 576 \\
\hline PL-I & D21103 & 5' TCCAAACCAACTGCCATTGTGTCC 3' & 5' GACACTCCACACTCATTCTTAAAGAC 3' & 595 \\
\hline PL-IV & U32679 & 5' TCCAAACCAACTGTGCTTGTGTCC 3' & 5' ACACTCATTCTTAAAGACAACTCGGCA 3' & 584 \\
\hline PL-II & M13749 & 5' GCACCAAATTACCGAATGTCCACT 3' & 5' TCAGCAGTTGTTGTTATAAATATCGCG 3' & 575 \\
\hline Proliferin-RP & AF139809 & 5' ATAAATGCCAGCGAGACTACCCTC 3' & 5' TCAAAATCCTGAGTAGCAGACATTATC 3' & 641 \\
\hline PLP-A & M13750 & 5' ATGAGAGCTAAACTGTTGAATGTC 3' & 5' GCACTTGCTTCGGATCAGTC 3' & 587 \\
\hline PLP-B & M31155 & 5' AGTGGGGCTGGGCGTGGTGA 3' & 5' TCTATTATAGATAAGTCTACACTTCAGTAG 3' & 581 \\
\hline PLP-C & M76537 & 5' GCATGTATGGTGGAAGACGGT 3' & 5' GCAATCTTTCCCAGTTATGAGACA 3' & 617 \\
\hline PLP-CV & U93351 & 5' GCATGTATGGTGGAAGACGGT 3' & 5' GCAATCTTTCCCAGTTATGAGACA 3' & 617 \\
\hline PLP-D & AB000107 & 5' CTTGCGGAAGAGGGCGGCT 3' & 5' GCAATCTTTCCCAGTTGTGAGACA 3' & 620 \\
\hline PLP-H & AB009889 & 5' GCATGTATGGTGGAAGAGGGT 3' & 5' GCAATCTTTTCCAGTTATGAGACA 3' & 617 \\
\hline $\mathrm{d} / \mathrm{tPRP}$ & L06441 & 5' CCTGCTTGTCACCTGGAAGAA 3' & 5' TTCTTTCCСTGTTATGCGACACAT 3' & 626 \\
\hline PLP-F & AF139808 & 5' AATAGCAATGAGACTGATGGCGAT 3' & 5' AGAATCTTCACTATTGATGGATAAGCA 3' & 650 \\
\hline PLP-I & AB019791 & 5' TGTTCATTGAAGATCTCTTTGACC 3' & 5' ATTATGAATGATACGGCACTTTAGG 3' & 548 \\
\hline PLP-J & AB019945 & 5' ACACCATATGACCAGATGTCCAAT 3' & 5' CCACTTGTTTTTAATAATGTTAGGCC 3' & 545 \\
\hline PLP-K & AF234635 & 5' ATATCCACCTGTGCAGAGAG 3' & 5' GCAGTTGTTTTGATTGAATATTTGGTA 3' & 590 \\
\hline PLP-L & AB022883 & 5' TGCCAGAAGGTCCTCAACTAC 3' & 5' TTCATTAGGCACAATTTTGTTTCTCAG 3' & 572 \\
\hline PLP-M & AF226608 & 5' TGCTTAGTAAGGAATGGGCGCTGC 3' & 5' GCACTTTACCATCTTGAGAGCAGTTTC 3' & 578 \\
\hline $\begin{array}{l}\text { Growth } \\
\text { hormone }\end{array}$ & V01237 & 5' TCCAGTCTGTTTGCCAATGCTGTG 3' & 5' AAAGCGGCGACACTTCTAGACC 3' & 530 \\
\hline
\end{tabular}

PL, placental lactogen; proliferin-RP, proliferin-related protein; PLP, prolactin-like protein; d/tPRP, decidual-trophoblast prolactin-related protein.

\section{Statistical analysis}

The data were analysed by analysis of variance. The source of variation from significant $F$ ratios was determined with the Newman-Keuls multiple comparison test (Keppel, 1973).

\section{Results}

The prolactin gene families of the mouse and rat consist of numerous members expressed in key tissues associated with pregnancy. These features were used to develop a hybridization-based assay for monitoring uteroplacental 


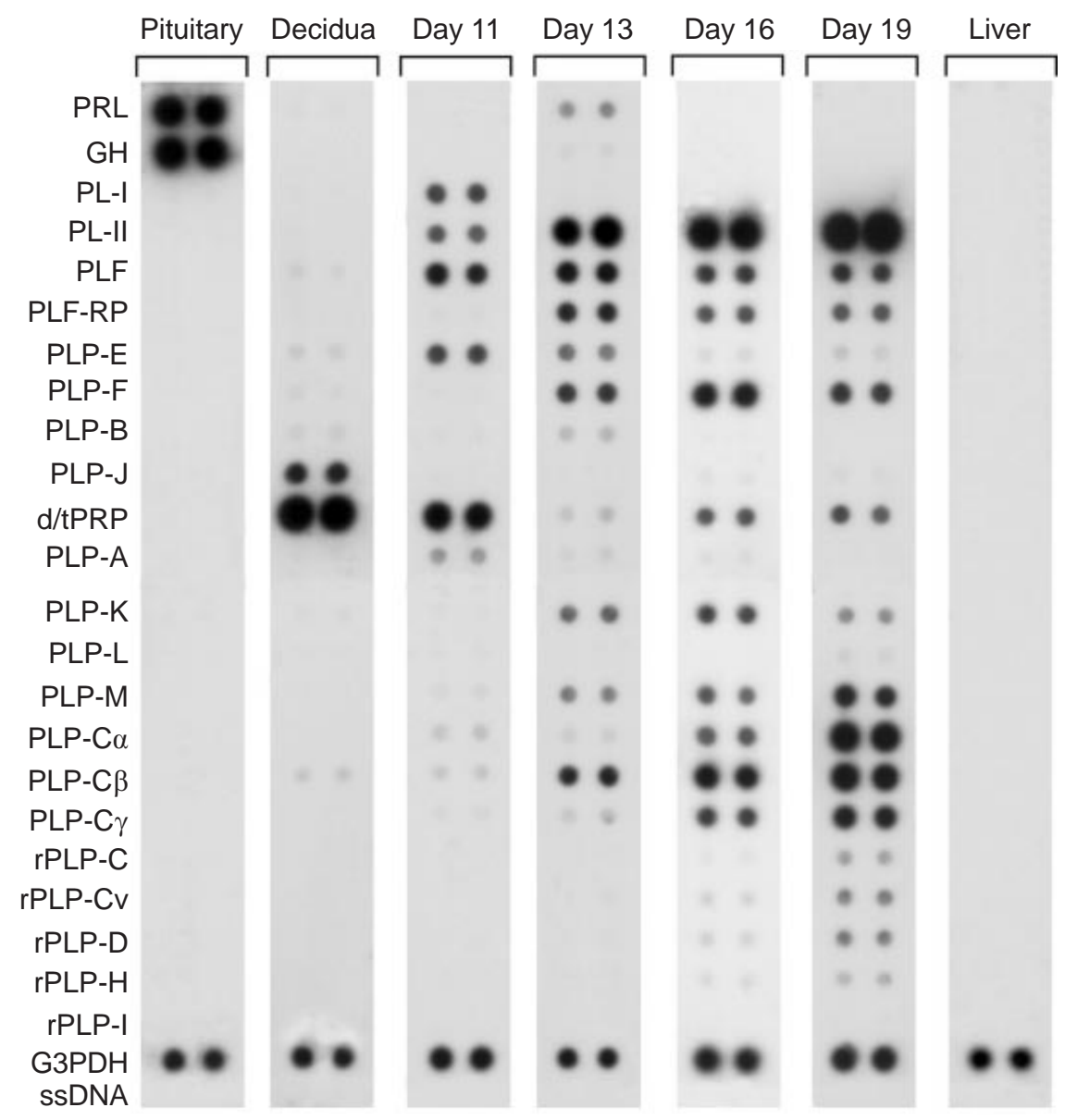

Fig. 1. Evaluation of mouse anterior pituitary, decidual and placental phenotypes with the prolactin (PRL) family miniarray assay. cDNAs for all members of the mouse PRL gene family and five unique members of the rat PRL gene family (rPLP-C, rPLP-Cv, rPLP-D, rPLP-H, rPLP-I) were isolated, characterized and spotted on to nylon membranes. Total RNA was prepared from mouse anterior pituitary, decidua from day 8 of gestation and placental tissues from day 11 , day 13 , day 16 and day 19 of gestation, and prolactin family expression assessed with the PRL family miniarray assay. Liver served as a control tissue for the procedure. Glyceraldehyde-3-phosphate dehydrogenase $(\mathrm{G} 3 \mathrm{PDH})$ served as an internal positive control. Salmon sperm DNA (ssDNA) was a negative background control for hybridization. Data presented in this figure are representative of at least three different experiments. $\mathrm{GH}$, growth hormone; PL, placental lactogen; PLF, proliferin; PLF-RP, proliferin-related protein; PLP, prolactin-like protein; $d /$ tPRP, decidual-trophoblast prolactin-related protein.

tissue and trophoblast cell prolactin family endocrine phenotypes.

\section{Analysis of uteroplacental tissue phenotypes with the prolactin family miniarray assay}

Prolactin family miniarrays were used to examine gene expression patterns in the anterior pituitary, uterine decidua and placental tissues of mice (Figs 1 and 2). Prolactin and growth hormone mRNAs were abundantly expressed in the anterior pituitary. Uterine decidual tissue expressed decidualtrophoblast PRP (d/tPRP) and PLP-J, whereas placental tissues showed a dynamic pattern of prolactin family gene activation (Figs 1 and 2). Placental expression patterns are organized in groups of functionally or structurally related prolactin family members (Fig. 2). Some members of the prolactin family exhibited reciprocal patterns of placental expression. PL-I, PLP-A and PLP-E mRNA abundance significantly declined as gestation advanced, whereas PL-II, PLP-F, PLP-C $\alpha$, PLP-C $\beta$, PLP-C $\gamma$, PLP-L and PLP-M mRNA abundance significantly increased as gestation advanced $(P<0.01)$. Other members of the prolactin family exhibited a more dynamic gestational pattern of gene expression. Proliferin, proliferin-RP, PLP-B and PLP-K increased from day 11 to day 13 of gestation and their expression was reduced during the later stages of pregnancy $(P<0.01)$. Prolactin family gene expression was not detected in the mouse liver. 

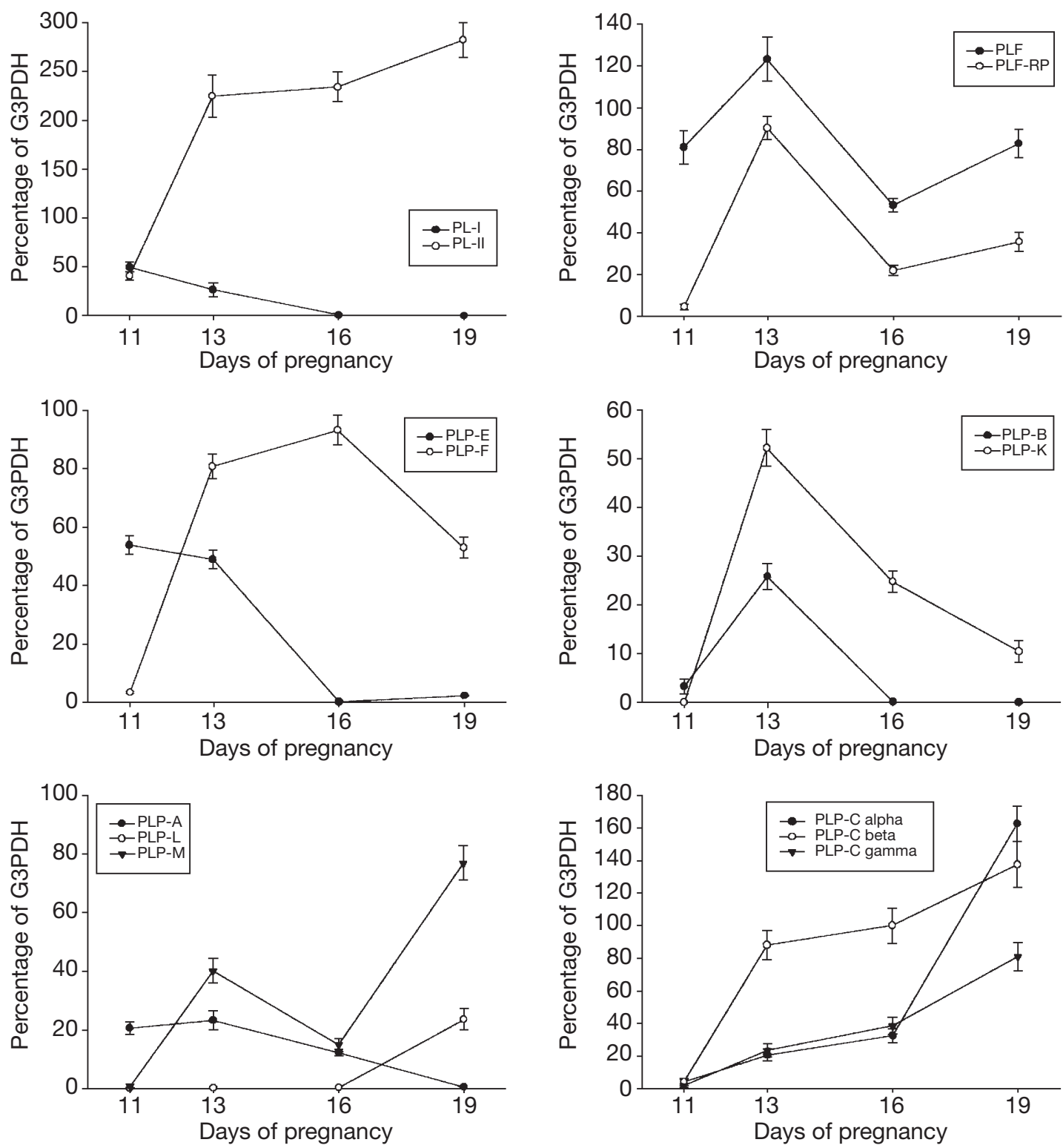

Fig. 2. Expression patterns of selected members of the prolactin (PRL) family during pregnancy in mice. Expression was determined by densitometry of PRL family miniarray assays. cDNAs for all members of the mouse PRL gene family and five unique members of the rat PRL gene family (rPLP-C, rPLP-Cv, rPLP-D, rPLP-H, rPLP-I) were isolated, characterized and spotted on to nylon membranes. Total RNA was prepared from mouse anterior pituitary, decidua from day 8 of gestation and placental tissues from day 11, day 13, day 16 and day 19 of gestation, and PRL family expression assessed with the PRL family miniarray assay. Results are organized in groups of functionally or structurally related PRL family members. Data are presented relative to glyceraldehyde-3-phosphate dehydrogenase $(\mathrm{G} 3 \mathrm{PDH})$ expression as means \pm SEM of six replicates. PL, placental lactogen; PLF, proliferin; PLF-RP, proliferin-related protein; PLP, prolactin-like protein.

The prolactin family endocrine phenotype of anterior pituitary, placental and liver tissues of the rat was assessed with the prolactin family miniarray (Fig. 3). Anterior pituitary tissues expressed abundant amounts of prolactin and growth hormone, whereas prolactin family gene expression was not detectable in the rat liver. Rat placental tissues are amenable to additional dissection. Dissected tissue compartments were analysed. On day 11 of gestation, chorioallantoic and choriovitelline placental tissues exhibited similar expression patterns, except for a reduction in PLP-A, PLP-L and PLP-M mRNA expression in choriovitelline placental tissues. Examination of prolactin family gene expression in chorioallantoic placental compartments revealed some unique features. Proliferin-RP and PLP-K 


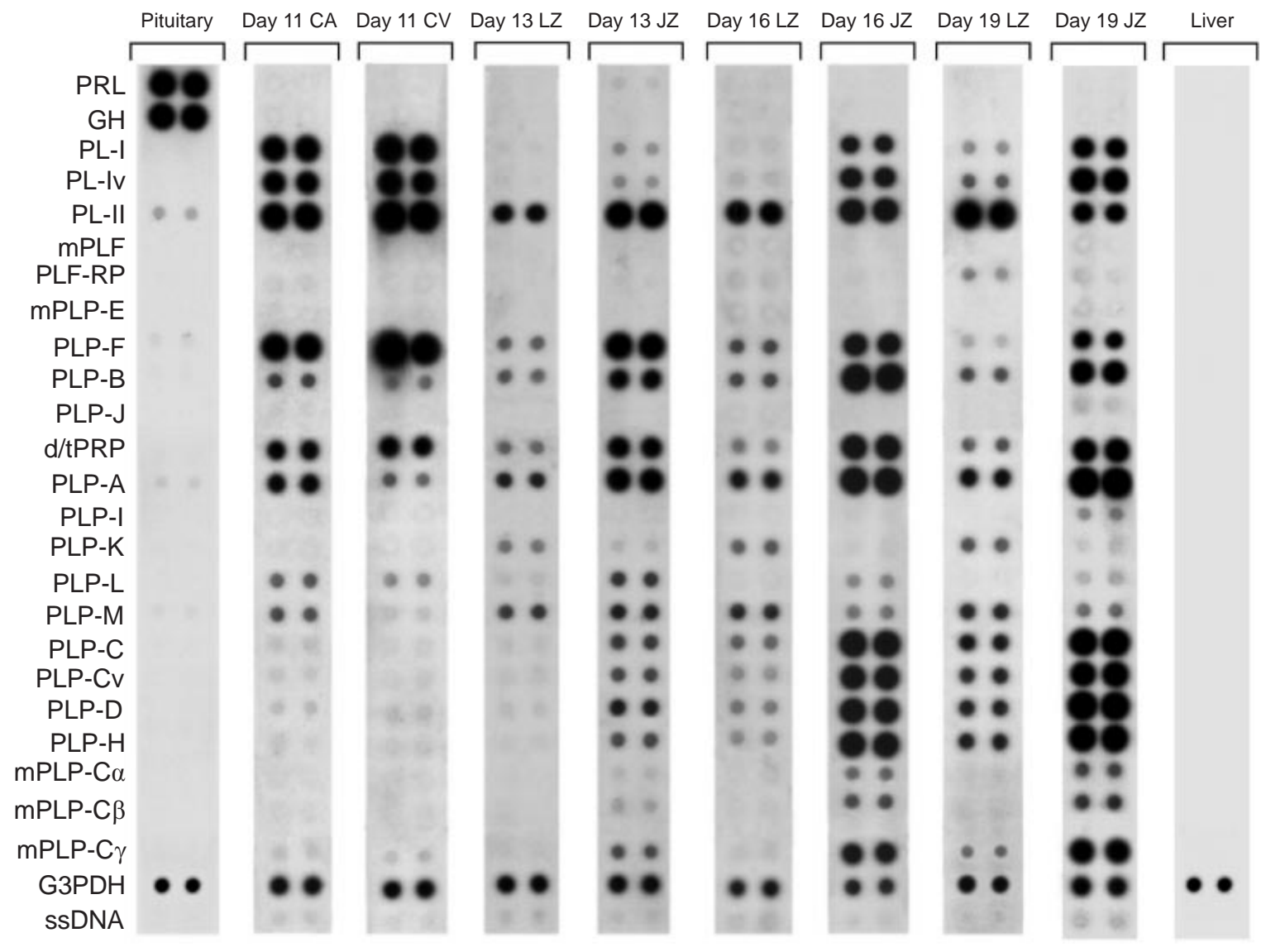

Fig. 3. Evaluation of rat anterior pituitary and placental phenotypes with the prolactin (PRL) family miniarray assay. cDNAs for all members of the rat PRL gene family and five unique members of the mouse PRL family (mPLF, mPLP-E, $\mathrm{mPLP}-\mathrm{C} \alpha, \mathrm{mPLP}-\mathrm{C} \beta, \mathrm{mPLP}-\mathrm{C} \gamma$ ) were isolated, characterized and spotted on to nylon membranes. Total RNA was prepared from rat anterior pituitary and placental tissues from day 11, day 13, day 16 and day 19 of gestation. Day 11 placental tissues were further dissected into chorioallantoic (CA) and choriovitelline (CV) placentae and tissues obtained from day 13, day 16 and day 19 of gestation into labyrinth zone (LZ) and junctional zone (JZ) compartments. Liver served as a control tissue for the procedure. Glyceraldehyde-3-phosphate dehydrogenase (G3PDH) served as an internal positive control. Salmon sperm DNA (ssDNA) was a negative background control for hybridization. Data presented in this figure are representative of at least three different experiments. $\mathrm{GH}$, growth hormone; PL, placental lactogen; PLF, proliferin; PLF-RP, proliferin-related protein; PLP, prolactin-like protein; d/tPRP, decidual-trophoblast prolactin-related protein.

gene expression were restricted to the labyrinth zone, whereas PLP-I and PLP-L mRNAs and rat mRNAs hybridizing with mouse PLP-C $\alpha$ and PLP- $\beta$ predominated in the junctional zone.

\section{Analysis of trophoblast cell phenotypes with the prolactin family miniarray assay}

Rcho-1 trophoblast cells can be manipulated to proliferate or differentiate depending upon the culture conditions (Peters et al., 2000). The prolactin family miniarray assay was used to evaluate the prolactin family endocrine phenotype of proliferating and differentiating Rcho- 1 trophoblast cells (Figs 4 and 5). PL-I, PL-II, PLP-A, PLP-D, PLP-F and PLP-M showed a progressive and significant increase in expression from the onset of culture until days $16-20 \quad(P<0.01)$; and each member showed a subsequent significant decrease in expression by day 24 of culture $(P<0.01)$. The pattern of prolactin family gene expression was consistent with differentiation along the trophoblast giant cell lineage.

The prolactin family miniarray assay was also used to evaluate the prolactin family endocrine phenotype of a mouse trophoblast cell culture model (Fig. 6). Mouse TS cells were examined in proliferating and differentiating cells. Prolactin family gene expression was not detectable in proliferating TS cells. However, after 6 days of culture under differentiating conditions, PL-I, PL-II, proliferin, proliferinRP, PLP-E and PLP-M mRNAs were detected. The TS cell prolactin family endocrine phenotype was consistent with a trophoblast giant cell mode of differentiation.

\section{Discussion}

The prolactin gene family has undergone an expansion in mice and rats (Soares and Linzer, 2001). Members of the 


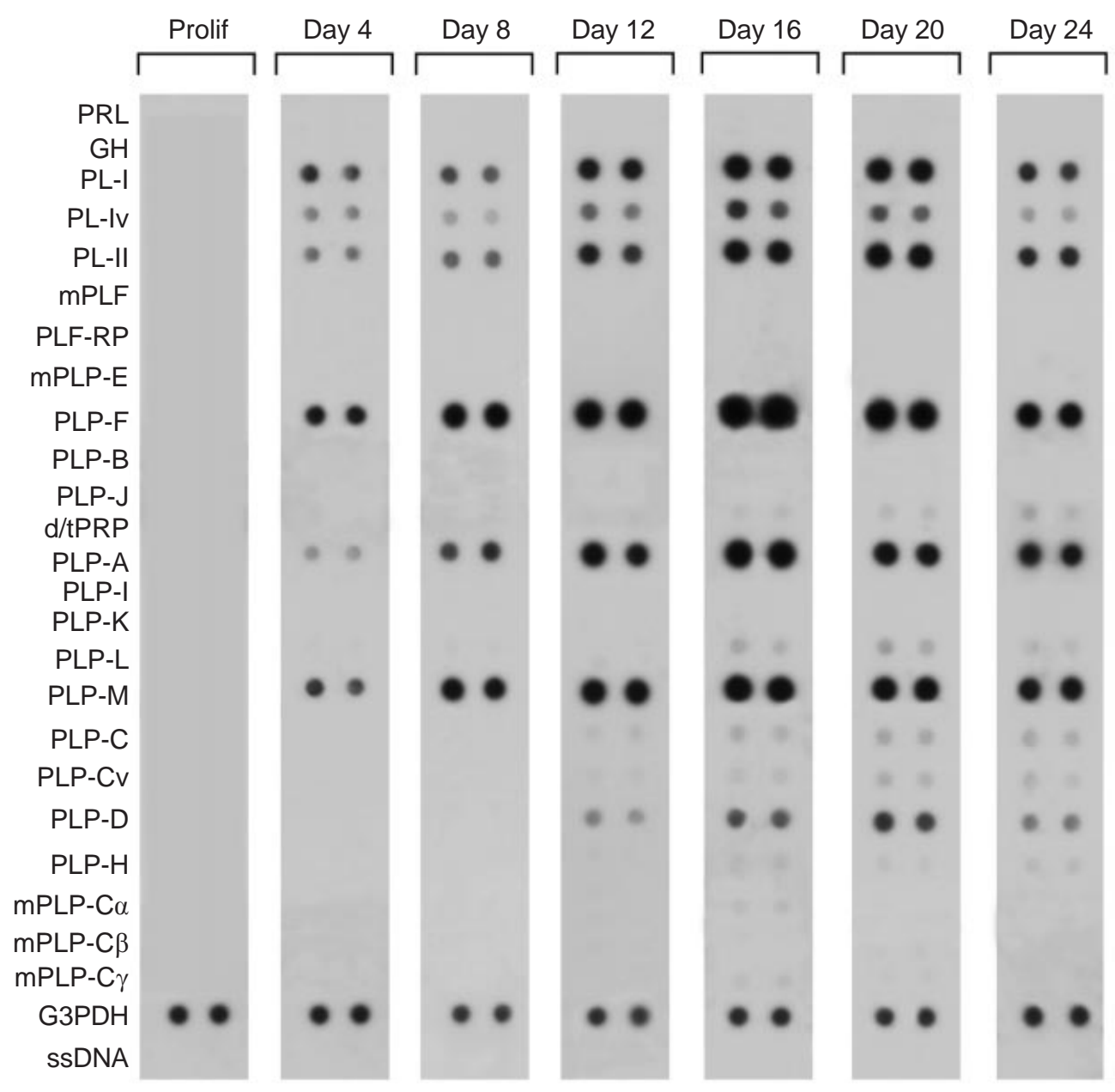

Fig. 4. Assessment of rat trophoblast cell phenotypes with the prolactin (PRL) family miniarray assay. Rcho-1 trophoblast cells were analysed under proliferative or differentiating conditions. Proliferating Rcho-1 trophoblast cells were maintained in RPMI-1640 supplemented with 20\% fetal bovine serum. Rcho-1 trophoblast cells were induced to differentiate by replacement of the culture medium with NCTC-135 containing 10\% horse serum. Cells were harvested under proliferative (Prolif) conditions (day 1 of culture) and on days 4, 8, 12, 16, 20 and 24 of differentiation. Total RNA was isolated and PRL family gene expression assessed with the PRL family miniarray assay. The PRL family minarray consisted of cDNAs for all members of the rat PRL gene family and five unique members of the mouse PRL family (mPLF, mPLP-E, mPLP-C $\alpha$, mPLP-C $\beta, m P L P-C \gamma$ ). Glyceraldehyde3-phosphate dehydrogenase $(\mathrm{G} 3 \mathrm{PDH})$ served as an internal positive control. Salmon sperm DNA (ssDNA) was a negative background control for hybridization. Data presented in this figure are representative of at least three different experiments. $\mathrm{GH}$, growth hormone; PL, placental lactogen; PLF, proliferin; PLF-RP, proliferin-related protein; PLP, prolactin-like protein; d/tPRP, decidualtrophoblast prolactin-related protein.

family are expressed in cell- and temporal-specific patterns (Soares et al., 1991, 1996; Soares and Linzer, 2001). These unique expression patterns were used in the present study to derive a simple array based hybridization assay for evaluating phenotypes of uteroplacental tissues and trophoblast cells.

The prolactin family miniarray assays demonstrate the specificity of expression patterns in the anterior pituitary, uterine decidua and developing chorioallantoic placenta. Tissue- and temporal-specific patterns of gene expression were evident. Prolactin and growth hormone were predominantly expressed in the anterior pituitary; $d / t$ PRP and
PLP-J were abundantly expressed in uterine decidual tissue, and the remaining members of the prolactin family were expressed in dynamic gestational-specific patterns within the developing chorioallantoic placenta. Enrichment for specific placental structures was achieved by mechanical dissection and provided some additional insights into expression profiles. For example, the labyrinthine zonerestricted expression patterns of PLP-K and proliferin-RP (Dai et al., 2000; Sahgal et al., 2000) were verified. Overall expression patterns determined with the prolactin family miniarray assays were similar to those previously reported 


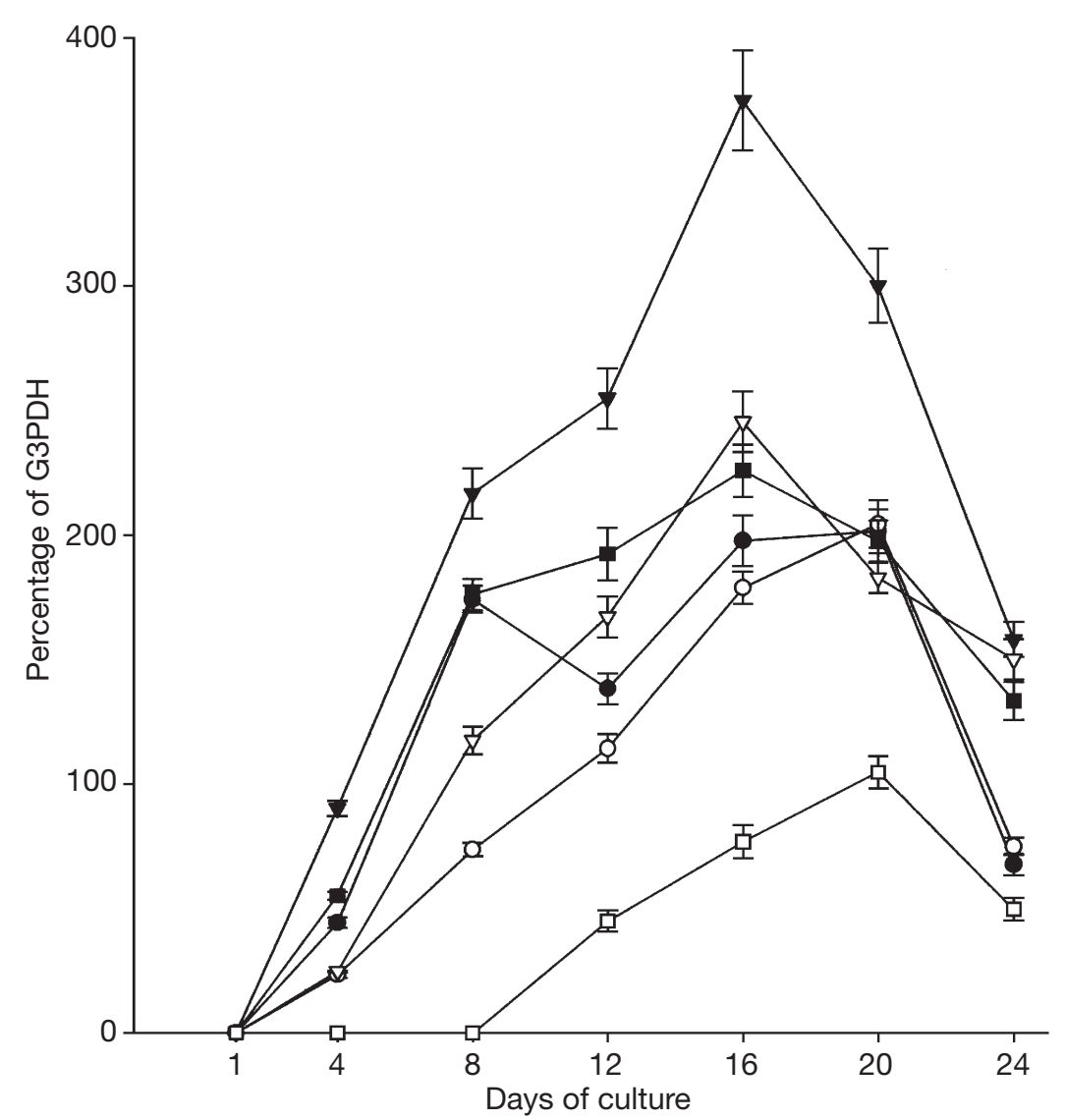

Fig. 5. Expression patterns of selected members of the prolactin (PRL) family during rat trophoblast cell differentiation. @: PL-I; O: PL-II; $\mathbf{\nabla : ~ P L P - F ; ~} \nabla$ : PLP-A; $\mathbf{\square}:$ PLP-M; $\square$ : PLP-D. Expression was determined by densitometry of PRL family miniarray assays as shown in Fig. 4. Rcho-1 trophoblast cells were analysed under proliferative or differentiating conditions. Proliferating Rcho-1 trophoblast cells were maintained in RPMI-1640 supplemented with 20\% fetal bovine serum. Rcho-1 trophoblast cells were induced to differentiate by replacement of the culture medium with NCTC-135 containing 10\% horse serum. Cells were harvested under proliferative conditions (day 1 of culture) and on days 4, 8, 12, 16, 20 and 24 of differentiation. Total RNA was isolated and PRL family gene expression assessed with the PRL family miniarray assay. The PRL family minarray consisted of cDNAs for all members of the rat PRL gene family and five unique members of the mouse PRL family (mPLF, mPLP-E, mPLP-C $\alpha$, mPLP-C $\beta$, mPLP-C $\gamma$ ). Data are presented relative to glyceraldehyde-3-phosphate dehydrogenase $(\mathrm{G} 3 \mathrm{PDH})$ expression as means \pm SEM of six replicates. PL, placental lactogen; PLP, prolactin-like protein.

for each member of the prolactin family (see Soares et al., 1991, 1996; Soares and Linzer, 2001). The miniarray assay also provided new insights into the relative expression among members of the prolactin family. Some members of the family were abundantly expressed relative to other family members. Relative gene expression was gestationally dependent. The prolactin family miniarray assay should prove to be a useful means of assessing placental phenotypes in normal and genetically mutant mice and rats.

The prolactin family miniarray assay is an excellent means of assessing the differentiation status of trophoblast cells. The chorioallantoic placenta comprises two structurally and functionally distinct regions (Soares et al., 1996): (i) junctional zone and (ii) labyrinth zone. The junctional zone is located adjacent to the decidua basalis and contains trophoblast cells and maternal vascular channels but is devoid of fetal vessels, whereas the labyrinth zone is located adjacent to the developing embryo and contains trophoblast cells, maternal vascular channels and fetal vessels. A number of differentiated trophoblast cells can be identified in the junctional zone (trophoblast giant cells, spongiotrophoblast cells, glycogen cells) and in the labyrinth zone (labyrinthine trophoblast stem cells, labyrinthine trophoblast giant cells, syncytiotrophoblast cells). Each of these types of cell has unique functional and morphological attributes. The trophoblast giant cell is the first differentiated 


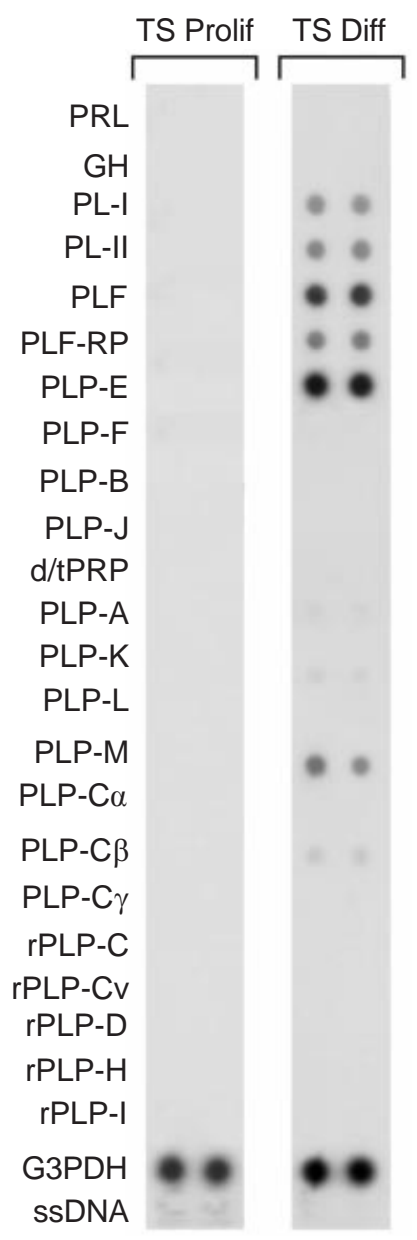

Fig. 6. Assessment of mouse trophoblast stem (TS) cell phenotypes with the prolactin (PRL) family miniarray assay. Proliferating (TS Prolif) and differentiating (TS Diff) cells were evaluated. Proliferating TS cells were maintained in RPMI-1640 supplemented with medium conditioned by mouse embryonic fibroblasts, fibroblast growth factor 4 (FGF-4), heparin and 20\% fetal bovine serum. TS cells were induced to differentiate after removal of the conditioned medium, FGF-4 and heparin supplements. Cells were harvested, total RNA isolated and PRL family expression assessed with the PRL family miniarray assay. The PRL family miniarray consisted of cDNAs for all members of the mouse PRL gene family and five unique members of the rat PRL gene family (rPLP-C, rPLP-Cv, rPLP-D, rPLP-H, rPLP-I). Glyceraldehyde-3-phosphate dehydrogenase $(\mathrm{G} 3 \mathrm{PDH})$ served as an internal positive control. Salmon sperm DNA (ssDNA) was a negative background control for hybridization. Data presented in this figure are representative of at least three different experiments. $\mathrm{GH}$, growth hormone; PL, placental lactogen; PLF, proliferin; PLF-RP, proliferin-related protein; PLP, prolactin-like protein; d/tPRP, decidual-trophoblast prolactin-related protein.

type of cell to arise during development of the trophoblast lineage. Giant cells possess invasive and endocrine activities and are critically situated at the maternal interface. Spongiotrophoblast cells are morphologically distinct from trophoblast giant cells. However, similar to trophoblast giant cells, spongiotrophoblast cells exhibit endocrine activities, including expression of a subset of members of the prolactin gene family. Glycogen cells accumulate glycogen and are a potential energy reserve. Syncytial trophoblast cells are multinucleated cells and are implicated in bidirectional transport of nutrients and wastes. Two in vitro cell culture models were evaluated in the present study. Rcho- 1 trophoblast cells are a rat trophoblast stem cell population that can be manipulated to differentiate (Faria and Soares, 1991; Peters et al., 2000). As Rcho-1 trophoblast cells progressed from a proliferative state to a differentiated state, they exhibited an increased expression of specific members of the prolactin family. PL-I, PL-II, PLP-A, PLP-F and PLP-M mRNAs showed prominent increases in expression as trophoblast cells differentiated. The differentiationdependent activation of PL-I, PL-II, PLP-A and PLP-F has previously been reported (Faria and Soares, 1991; Sahgal et al., 2000); however, this is the first demonstration that PLP-M mRNA is increased in differentiated trophoblast cells. Expression of other prolactin family members was increased to a lesser extent and later in the differentiation scheme (for example, PLP-L and members of the PLP-C subfamily, d/tPRP, PLP-C, PLP-CV, PLP-D, and PLP-H). The absence of expression of prolactin, PLP-B, PLP-I, PLP-J, PLP-K and proliferin-RP reinforces the restriction of Rcho-1 trophoblast cell differentiation to the trophoblast giant cell lineage (Faria and Soares, 1991; Peters et al., 2000). Prolactin is expressed in the lactotroph cell lineage and expression is low in decidua (Prigent-Tessier et al., 1999; Dasen and Rosenfeld, 2001); PLP-B is expressed during early decidual cell development and in the spongiotrophoblast cell lineage of the chorioallantoic placenta (Croze et al., 1990; Cohick et al., 1997); PLP-I expression is restricted to late gestation spongiotrophoblast cells (Wiemers et al., in press); PLP-J is expressed in a decidual cell-restricted pattern (Hiraoka et al., 1999; Toft and Linzer, 1999; Dai et al., 2000); and PLP-K and PLF-RP gene activation is limited to labyrinthine trophoblast in the rat chorioallantoic placenta (Dai et al., 2000; Sahgal et al., 2000). The prolactin family miniarray was also used to evaluate the differentiation of mouse TS cells. TS cells are capable of differentiating into each of the trophoblast cell lineages (Tanaka et al., 1998). Prolactin family gene expression was not detectable in proliferating TS cells. However, in vitro differentiated TS cells expressed several members of the prolactin family. The phenotype of the differentiated TS cells was consistent with progression along the trophoblast giant cell lineage.

Expression of the prolactin family was not detectable in the liver. An assortment of other normal adult tissues (brain, thymus, heart, lung, stomach, intestine, pancreas, spleen, kidney, adrenal, muscle, adipose, prostate gland, testis, ovary and epididymis) was also surveyed with the prolactin family miniarray assay. These tissues exhibit minimal to non-detectable expression of the prolactin family (data not shown). There is some evidence for the reactivation of proliferin, a member of the prolactin family, in tissues undergoing pathological processes (Fassett et al., 2001; Toft et al., 2001). Such a finding is not surprising since the action of proliferin on endothelial cells during the establishment of 
pregnancy may also be relevant to the control of endothelial cells in diseased tissues. Other members of the prolactin family regulate haematopoietic, immune and inflammatory cells (Soares and Linzer, 2001) and by analogy may also be reactivated during the pathogenesis of disease. The prolactin family miniarray may prove to be a useful tool for screening the activation of prolactin family members in pathological tissue specimens.

The prolactin family miniarray assays provided insights about orthologous genes in mice and rats. Mouse and rat orthologues have been identified for most, but not all, members of the prolactin family. In the mouse prolactin family miniarray rat prolactin family paralogues, which are not orthologous to any known mouse prolactin family members, were included. Similarly, in the rat prolactin family miniarray mouse prolactin family paralogues, which are not orthologous to any known rat prolactin family members, were included. In some cases evidence was found for orthologous genes in both species, whereas in other cases there was support for the presence of nonorthologous prolactin family paralogues. Genes orthologous to proliferin and PLP-E do not appear to be expressed in rats. PLP-E and PLP-F are structurally related and represent part of a placental signalling system involved in the regulation of haematopoiesis (Lin and Linzer, 1999; Bittorf et al., 2000). In mice, PLP-E is expressed from early postimplantation stages to midgestation, while PLP-F expression is increased only during the later stages of gestation. In contrast, during pregnancy in rats, PLP-F is increased from early postimplantation stages until the end of pregnancy. Thus, in mice and rats, two slightly different strategies may be used to regulate haematopoiesis during pregnancy (a dual complementary hormone system versus a single hormone system). Additional marked species differences in gestational profiles for PLP-A and PLP-B were also apparent. In mice, expression of both hormones peaks at midgestation, whereas in rats PLP-A and PLP-B expression predominates during the latter half of pregnancy. Hybridization signals were observed for rat placental RNA samples with mouse PLP-C subfamily members. Whether these hybridization signals indicate the presence of rat orthologues or cross-hybridization with rat PLP-C subfamily members remains to be determined. Based on these observations, we propose that the prolactin family miniarray assay may be a useful tool for discovering orthologous genes in other species.

There are some limitations to the prolactin family miniarray assay. The assay is based on nucleotide hybridization and thus discrimination of closely related transcripts is problematic. This is particularly evident for relatives of the PL-I and PLP-C subfamilies. Additionally, the assay does not replace techniques that are characterized by greater specificity (RT-PCR) or techniques that provide precise cellular localization (for example, in situ hybridization).

In conclusion, the prolactin family miniarray assay is a technique that provides meaningful information about placental and trophoblast endocrine cell phenotypes and may be useful for other purposes including the identifica- tion of new tissue sources of prolactin family members and the discovery of orthologous CDNAs in other species.

This work was supported by grants from the Andrew Mellon Foundation, J.B. Reynolds Foundation and the National Institute of Child Health and Human Development (HD20676, HD33994, HD37123, HD37678, HD38430, HD39878). The authors wish to thank D. I. H. Linzer for CDNAs to mouse PL-I, PL-II, proliferin and proliferin-RP and K. Shiota for CDNAs to rat PLP-D and rat PLP-H. D. Watne and D. Warn are acknowledged for assistance with the preparation of the graphic materials.

\section{References}

Bittorf T, Jaster R, Soares MJ, Seiler J, Brock J, Friese K and Müller H (2000) Induction of erythroid proliferation and differentiation by a trophoblastspecific cytokine involves activation of the JAK/STAT pathway Journal of Molecular Endocrinology 25 253-262

Chomczynski P and Sacchi N (1987) Single-step method of RNA isolation by acid guanidinium thiocyanate-phenol-chloroform extraction Analytical Biochemistry 162 156-159

Cohick CB, Xu L and Soares MJ (1997) Placental prolactin-like protein-B: heterologous expression and characterization of placental and decidual species Journal of Endocrinology 152 291-302

Croze F, Kennedy TG, Schroedter IC and Friesen HG (1990) Expression of rat prolactin-like protein-B in deciduoma of pseudopregnant rat and in decidua during early pregnancy Endocrinology 127 2665-2672

Dai G, Chapman BM, Liu B, Orwig KE, Wang D, White RA, Preuett B and Soares MJ (1998) A new member of the mouse prolactin (PRL)-like protein-C subfamily, PRL-like protein-Ca: structure and expression Endocrinology 139 5157-5163

Dai G, Wang D, Liu B, Kasik JW, Müller H, White RA, Hummel GS and Soares MJ (2000) Three novel paralogs of the rodent prolactin gene family Journal of Endocrinology 166 63-75

Dasen JS and Rosenfeld MG (2001) Signaling and transcriptional mechanisms in pituitary development Annual Review Neuroscience 24 327-355

Faria TN and Soares MJ (1991) Trophoblast cell differentiation: establishment, characterization and modulation of a rat trophoblast cell line expressing members of the placental prolactin family Endocrinology 129 2895-2906

Faria TN, Deb S, Kwok SCM, Talamantes F and Soares MJ (1990) Ontogeny of placental lactogen-I and placental lactogen-II expression in the developing rat placenta Developmental Biology 141 279-291

Fassett JT and Nilsen-Hamilton M (2001) Mrp3, a mitogen-regulated protein/proliferin gene expressed in wound healing and in hair follicles Endocrinology 142 2129-2137

Hamlin GP and Soares MJ (1995) Regulation of DNA synthesis in proliferating and differentiating trophoblast cells: involvement of transferrin, transforming growth factor- $\beta$ and tyrosine kinases Endocrinology 136 322-331

Hamlin GP, Lu X-J, Roby KF and Soares MJ (1994) Recapitulation of the pathway for trophoblast giant cell differentiation in vitro: stage-specific expression of members of the prolactin gene family Endocrinology 134 2391-2396

Hiraoka Y, Ogawa M, Sakai Y, Takeuchi Y, Komatsu N, Shiozawa M, Tanabe K and Aiso S (1999) PLP-I: a novel prolactin-like gene in rodents Biochimica et Biophysica Acta 1447 291-297

Keppel G (1973) Design and Analysis Prentice Hall, Englewood Cliffs, New Jersey

Lin J and Linzer DIH (1999) Induction of megakaryocyte differentiation by a novel pregnancy-specific hormone Journal of Biological Chemistry 274 $21485-21489$

Orwig KE, Ishimura R, Müller H, Liu B and Soares MJ (1997) Identification and characterization of a mouse homolog for decidual/trophoblast PRLrelated protein Endocrinology 138 5511-5517

Peters TJ, Chapman BM and Soares MJ (2000) Trophoblast differentiation: an in vitro model for trophoblast giant cell development. In Develop- 
mental Protocols pp 301-311 Eds RS Tuan and CW Lo. Humana Press Inc., Totowa, NJ

Prigent-Tessier A, Tessier C, Hirosawa-Takamori M, Boyer C, FergusonGottschall S and Gibori G (1999) Rat decidual prolactin. Identification, molecular cloning and characterization Journal of Biological Chemistry $27437982-37989$

Sahgal N, Knipp GT, Liu B, Chapman BM, Dai G and Soares MJ (2000) Identification of two new nonclassical members of the rat prolactin family Journal of Molecular Endocrinology 24 95-105

Soares MJ and Linzer DIH (2001) Rodent prolactin family and pregnancy. In Prolactin pp 139-167 Ed. ND Horseman. Kluwer Academic Publishers, Norwell, MA

Soares MJ, Faria TN, Roby KF and Deb S (1991) Pregnancy and the prolactin family of hormones: coordination of anterior pituitary, uterine and placental expression Endocrine Reviews 12 402-423

Soares MJ, Chapman BM, Rasmussen CA, Dai G, Kamei T and Orwig KE (1996) Differentiation of trophoblast endocrine cells Placenta 17 277-289

Soares MJ, Müller H, Orwig KE, Peters TJ and Dai G (1998) The uteroplacental prolactin family and pregnancy Biology of Reproduction 58 273-284
Tanaka S, Kunath T, Hadjantonakis A-K, Nagy A and Rossant J (1998) Promotion of trophoblast stem cell proliferation by FGF4 Science $\mathbf{2 8 2}$ 2072-2075

Toft DJ and Linzer DIH (1999) Prolactin (PRL)-like protein J, a novel member of the PRL/growth hormone family, is exclusively expressed in maternal decidua Endocrinology 140 5095-5101

Toft DJ, Rosenberg SB, Bergers G, Volpert O and Linzer DIH (2001) Reactivation of proliferin gene expression is associated with increased angiogenesis in a cell culture model of fibrosarcoma tumor progression Proceedings National Academy of Science USA 98 13 055-13059

Wiemers DO, Shao L-J, Ain R, Dai G and Soares MJ (2002) The mouse prolactin gene family locus Endocrinology 143 (in press)

Received 8 May 2002.

First decision 16 July 2002.

Revised manuscript received 14 August 2002.

Accepted 16 September 2002. 